\title{
Utilizing Research to Facilitate Organizational Change
}

\author{
Genevieve Nielsen ${ }^{1}$, Fiona Currie ${ }^{1}$, Kaye Ervin $^{2 *} \&$ Alison Koschel $^{2}$ \\ ${ }^{1}$ Cobram District Health, Cobram, Victoria, Australia \\ ${ }^{2}$ University of Melbourne, Shepparton, Victoria, Australia \\ ${ }^{*}$ Kaye Ervin, E-mail: ervink@ @umehealth.org.au
}

\begin{abstract}
This study aimed to facilitate organisational change through research to implement a workplace smoking ban. Previous appeals to the executive management had been unsuccessful, as the health service complied with legal requirements. This small exploratory research study, utilized the employee survey developed by QUIT Victoria, to gather evidence of staff opinions about workplace smoking. Approximately 25\% of the workforce smoked. The majority of the workforce in the study supported a workplace smoking ban, citing adverse effects of smoking on them and the environment. Staff also support quit smoking initiatives for staff and a small percentage of those who smoke (27\%) reported it would encourage them to quit. Four staff reported that a workplace smoking ban would create difficulties for them, highlighting the importance of support for these staff. A smoke free workplace policy was introduced as a result of the research project. Utilizing a research approach, facilitated positive change for local level workforce and workplace issues.
\end{abstract}

\section{Keywords}

rural research, smoking cessation, workplace change

\section{Introduction}

It is accepted that research informs clinical practice (Funk, Champagne, Wiese, \& Tornquist, 1991), however it is used less often to facilitate organizational change. The importance of health research utilisation in policy-making, and of understanding the mechanisms involved, is increasingly recognised (Hanney, Gonzalez-Block, Buxton, \& Kogan, 2003). Organisations less likely to utilise research evidence are shown to have centralisation of decision making (Dobbins, Ciliska, \& Mitchell, 1998; Regan \& Rodriguez, 2011). Decentralised models are shown to include the ability for local problems to be addressed quickly and easily (Vinson, 2004). Research utilisation is facilitated by organisational commitment (Dobbins et al., 1998) but requires time and resources (Royle \& Blythe, 1998), especially to achieve change (Bryar, Closs, Baum, Cooke, Griffiths, \& Hostick, 2003).

Organizational change is often driven by regulatory agencies, such as state health departments (Regan \& Rodriguez, 2011) not through ground up approaches, such as identified local needs. Frequently, research projects have little bearing on day to day practice and usefulness of findings can be problematic if the research is not conducted at a local level (Chambers, 1994). Local level research enable participants to 
identify issues in their own environments and respond to specific needs (Department of Human Services, 2005).

Employees at a small rural health service in northern Victoria identified that workplace smoking was problematic for multi factorial reasons. Approximately $25 \%$ of the workforce smoked. The primary designated smoking area at the health service was located next to the palliative care unit and operating theatre. Staff and patients frequently complained about smoking in this area. Most health services in Victoria had smoke free environments which had been enforced for many years. Although the Tobacco Act 1987 (Victorian Government, 2005) was amended in 2015 to include prohibition on smoking within four metres of the entrance to public hospitals, most health services in Victoria introduced total workplace smoking bans in 2010. The rationale for smoking prohibition stems from research which indicates smoking is a leading cause of preventable death and disease, the need to set an example for communities and the harmful effects of second-hand smoke exposure (McGhee \& Hedley, 2008; Cancer Council of Victoria, 2008). Published research on the effects of smoking bans in Australia is limited (Cancer Council of Victoria, 2008). Existing literature shows much of the decline in smoking prevalence is attributed to tobacco control policy (Levy \& Boyle, 2012), with an increasing body of evidence that the development of smoke free policies in the work place protect non-smokers from second hand smoke (Babb, 2014). Studies have shown that the implementation of smoke free policies can increase cessation and reduce smoking prevalence among workers (Bauer, Hyland, Li, Steger, \& Cummings, 2005).

Staff at the small rural health service had requested management to implement workplace smoking bans due to previous complaints, but management viewed current policy as compliant with minimum standards. Funding from the Australian nursing and midwifery work force provided the necessary resources for a staff member to partner with a university to introduce evidence based research to facilitate change. Previous literature acknowledges extra time, resources and collaboration with academic intuitions results in greater success of implementation of research findings (Royle \& Blythe, 1998).

This study aimed to facilitate organisational change through research to implement a workplace smoking ban. Further to the study itself all interventions introduced were evidence based (USA Government, 2013).

\section{Method}

\subsection{Context and Setting of the Study}

The setting of the study was a small rural health service in Northern Victoria. The health service employed approximately 208 staff members. The service is comprised of community health centre, a medical super clinic, a residential aged care facility and a 12 bed acute care facility.

\subsection{Design and Governance}

A Quasi experimental design was used for the study. An advisory group was convened to govern the research project and was comprised of the Director of Clinical services, Four Unit Managers, a Human 
Resource Officer, a Quality Improvement Co-ordinator and a Research Academic. Governance was also provided by the funding body (Nursing Midwifery workforce) and an ethics advisory group.

\subsection{Ethical Approval}

Ethical approval to conduct the study was provided by the University Of Melbourne, Human Ethics Advisory Group. All research abided by the Helsinki declaration on human research.

\subsection{Survey Tool}

An employee survey developed by QUIT Victoria was utilized for the study (QUIT, 2015) with the addition of demographic questions and stages of change (Daoud, Hayek, Sheik Muhammad, Abu-Saad, Osman, \& Thrasher, 2010). There is no evidence that the survey utilised has not been validated, and no psychometric testing of the tool was undertaken for the purposes of this small study. The intention of the survey was to determine staff opinions and behaviour in the local context for local application and the results were not intended to be generalisable.

The short seven question survey asked smoking status, the amount smoked, the personal adverse effect of smoking, opinions on smoke free locations, support for smoking cessation, and the time frame to introduce a smoke free policy.

\subsection{Recruitment}

The survey and a plain language statement describing the study was attached to all staff payslips. There were 142 payslips for the pay period of the study. Staff were assured that their participation was voluntary and their decision to participate or not would not affect current or future employment. Surveys were returned anonymously via a self addressed envelope.

\subsection{Analysis}

Data from the surveys was entered into SPSS V21. Descriptive statistics and frequencies were generated.

\section{Result}

Seventy three staff members returned completed surveys (51\% response rate). There were 61 female (84\%) and 12 male (16\%) respondents. The median age of respondents was 52 years (IQR 36.5, 56.5) which ranged from 18-66 years.

The majority of respondents came from the acute setting (22\%) followed by the Medical clinic (18\%), Aged Care Facility (14\%) and Community Health Centre (13\%), administration (10\%) and remaining $23 \%$ from other areas such as maintenance and environmental services.

Of those who responded $15 \%(\mathrm{n}=11)$ were smokers.

\subsection{Effects of Smoking}

Fifty eight percent $(n=42)$ reported that they were bothered by smoking in the workplace. The majority of those $(68 \%)$ reported that the smell of cigarettes affected them. They also reported that smoking was a poor example to the community (8\%), that it affected their own health (8\%), that staff took more breaks to smoke (8\%) and that it had an adverse affect on patients (5\%). 


\subsection{Trouble Locations and Support}

Respondents were asked an open ended question about which work locations were troublesome to them. Sixty one percent $(\mathrm{n}=45)$ reported that there were troublesome locations, the majority $(16 \%)$ cited the hospital grounds as problematic. Respondents were provided with seven locations and asked which location should be smoke free (respondents could choose as many as they thought applicable). The locations and responses are shown in Table 1. The respondents were also asked what type of support should be provided for staff who wish to quit or cut down, with eight responses provided. The types of support and responses are shown in Table 1. Respondents could indicate the preferred time period to introduce a smoke free work policy, with three options. Results are shown in Table 1.

Table 1. Responses to Problematic Locations, Type of Support and Time Frame for Policy Introduction

\begin{tabular}{lll}
\hline LOCATION & NUMBER & \% \\
\hline Entire site & 48 & 66 \\
Hospital Vehicles & 39 & 53 \\
4 metres from entrance & 38 & 52 \\
Outdoor dining areas & 32 & 44 \\
Outdoor covered areas & 22 & 30 \\
Car parks & 18 & 25 \\
TYPE OF SUPPORT & & \\
Quitting information & 49 & 67 \\
Free nicotine replacement therapy & 30 & 41 \\
Support with individual counselling at work & 28 & 38 \\
Subsidised nicotine replacement & 27 & 37 \\
Workshop courses & 25 & 34 \\
Group counselling at work & 19 & 26 \\
TIME PERIOD & & \\
3 months & 37 & 51 \\
1 month & 23 & 33 \\
More time & 9 & 12 \\
\hline
\end{tabular}

\subsection{Workplace Policy}

Respondents who identified as smokers were asked what effect a smoke free policy would have on them. Four respondents reported that it would have no effect, and four reported it would create difficulties for them. A further two reported that a policy would help them cut down and one reported it would encourage them to quit. 


\subsection{Implementation into Practice}

Although only half of the staff at the health service participated in the survey, the majority support a workplace smoking ban, citing adverse effects of smoking on them and the environment. Staff also supported quit smoking initiatives for staff members. The health service executive staff implemented a workplace smoking ban, with the approval of the board of management, due to the results of the survey. The project officer with support of management, assisted in the development of a smoke free policy, which was promoted with posters and information pamphlets. The physical environment was modified to support the smoke free policy by signage around the campus, removal of all butt bins and redevelopment of the outdoor areas that were previously smoking areas. A local pharmacist was consulted by the project officer to access subsidised nicotine replacement therapies for consenting staff and the project officer liaised with the Community Health centre to plan staff support for smoking cessation.

In conjunction with the introduction of the policy a number of workplace support programs were introduced under a Health and Well being program to assist staff in the implementation of the organizational change of a smoke free workplace. A workplace supported QUIT program gave information sessions on the various strategies to quit smoking and boost staff motivation to want to quit. These seminars ran over a 60-90 minutes timeframe and included subsidised nicotine replacement therapy. A month lifestyle modification program and was delivered as a group course, giving staff the motivation and support needed to make and maintain positive changes to adopt healthy behaviours and live a more active lifestyle. An optimism and resilience one day workshop was also presented to give staff a positive mindset along with a resilient can-do-attitude. The workplace health and well being programs were open to all staff members, smokers and non smokers.

\section{Discussion}

This small project demonstrated the ability of research to facilitate change. The survey findings determined that $58 \%$ of staff was bothered by smoke in the workplace and furthermore, greater than $60 \%$ reported that there were troublesome locations. Sixty six percent nominated that the entire campus should be smoke free. The findings indicated to management the need for policy change. Previous research suggests that the lack of exploration of the local context for implementation of research is the most significant barrier for transferring research into practice (Bryar et al., 2003; Green \& Seifert, 2005). It stands to reason that research findings related to participants' actual identified needs, within their practice context, will have greater acceptance. A wealth of cognitive research demonstrates that the greater the commonality between learning context and application context, the greater the likelihood that the new information will be spontaneously applied (McGrail, Jones, Robinson, Rickard, Burley, \& Drysdale, 2005). Previous studies have recommended that researchers have familiarity with the topic investigated, real interaction and participation with those being researched and that the usefulness of the research depends on the relevance of the findings (Vinson, 2004). 
A recognized limitation is the ability to conduct the research in the first instance. This project required financial resources for a dedicated staff member to conduct the study. Additionally, skill in all aspects of research methodology was required. These barriers were overcome by the funding from the nursing midwifery workforce and academic support from the University of Melbourne.

The implication of the study is that research can make a contribution to the policy-making process by policy formulation and implementation.

\section{Acknowledgements}

We acknowledge the Australian Government Department of Health University Department of Rural Health Program for funding.

\section{References}

Babb, S. D. (2014). Exposure to second hand smoke and attitudes toward smoke-free workplaces among employed U.S. adults: Findings from the national adult tobacco survey. Nicotine Tob Res, 16(10), 1307-1318.

Bauer, J. E., Hyland, A., Li, Q., Steger, C., \& Cummings, K. M. (2005). A longitudinal assessment of the impact of smoke-free worksite policies on tobacco use. Am J Public Health, 95(6), 1024-1029.

Bryar, R. et al. (2003). The Yorkshire BARRIERS project: Diagnostic analysis of barriers to research utilisation. Int J Nurs Stud, 40(1), 73-84.

Cancer Council of Victoria. (2008). Tobacco in Australia: Facts \& issues: A comprehensive online resource.

Chambers, R. (1994). The Origins and Practice of Participatory Rural Appraisal. World Dev, 22(7), 953-969.

Daoud, N., Hayek, S., Sheik Muhammad, A., Abu-Saad, K., \& Osman, A. (2010). Stages of change of the readiness to quit smoking among a random sample of minority Arab-male smokers in Israel. BMC Public Health, 15.

Department of Human Services. (2005). Community engagement and consultation: A guide for rural and regional communities. Program, Aust Gov.

Dobbins, M., Ciliska, D., \& Mitchell, A. (1998). Dissemination and use of research evidence for policy and practice by nurses: A model of development and implementation strategies. Can Nurses Assoc. Ottawa.

Funk, S. G., Champagne, M. T., Wiese, R. A., \& Tornquist, E. M. (1991). Barriers: The barriers to research utilization scale. Appl Nurs Res, 4(1), 39-45.

Green, L., \& Seifert, C. (2005). Translation of research into practice: Why we can't "just do it". Am Board Fam Pract, 18, 541-545.

Hanney, S. R., Gonzalez-Block, M. A., Buxton, M. J., \& Kogan, M. (2003). The utilisation of health research in policy-making: Concepts, examples and methods of assessment. Heal Res Policy Syst, 1, 
2.

Levy, D., \& Boyle, R. (2012). The role of public policies in reducing smoking. Am J Prev Med, $43(5$ Supp).

McGhee, S., \& Hedley, A. (2008). Second hand smoke. Int Encycl Public Heal, 669-674.

McGrail, M. R., Jones, R., Robinson, A., Rickard, C. M., Burley, M., \& Drysdale, M. (2005). The planning of rural health research: Rurality and rural population issues.

QUIT Victoria. (2015). Going Smoke Free: A Guide for Workplaces. Vic Heal, 1-16.

Regan, L. C., \& Rodriguez, L. (2011). Nurse empowerment from a middle-management perspective: Nurse managers' and assistant nurse managers' workplace empowerment views. Perm J., 15(1), 101-107.

Royle, J., \& Blythe, J. (1998). Promoting research utilisation in nursing: The role of the individual, organisation, and environment. Evid Based Nurs [Internet], 1(3), 71-72. Retrieved from http://www.ebn.bmj.com/content/1/3/71.full

USA government. (2013). Saving lives. Protecting people. Cent Dis Control Prev.

Victorian Government. (1987). Tobacco Act.

Vinson, T. (2004). Community adversity and resilience: The distribution of social disadvantage in Victoria \& New South Wales and the mediating role of social cohesion (p. 90). 